\title{
Alelopatia do extrato de eucalipto sobre a germinação de hortaliças
}

Allelopathy of eucalyptus extract on the germination of vegetables

Joene Alves Pereira ${ }^{1}$, Elisa Mitsuko Aoyama ${ }^{2}$, Karina Schmidt Furieri ${ }^{2}$, Marcos da Cunha Teixeira ${ }^{2}$

${ }^{1}$ Programa de Pós-Graduação em Rede em Ensino de Biologia (PROFBIO), Universidade Federal do Espírito Santo, São Mateus, Espírito Santo, Brasil.

${ }^{2}$ Universidade Federal do Espírito Santo, Departamento de Ciências Agrárias e Biológicas, São Mateus, Espírito Santo, Brasil.

Autor para correspondência: Joene Alves Pereira

Escola Estadual de Ensino Fundamental e Médio Ceciliano Abel de Almeida

Rua Jardim das Orquídeas, 187, Bairro Morada de Ribeirão, CEP 29.936-380,

São Mateus, Espírito Santo, Brasil

Tel: +55 27 99825-6234

Email: joenealvespereira@hotmail.com

Submetido em 21/12/2020

Aceito em 21/12/2020 


\section{RESUMO}

O trabalho trata-se de uma proposta de atividade investigativa sobre o tema Botânica para as aulas de Biologia do ensino médio, tendo como objetivo avaliar o potencial alelopático do extrato aquoso de Eucalyptus sobre a germinação de sementes de hortaliças (alface, rúcula, rabanete e couve), por meio de uma atividade experimental investigativa. Apresenta metodologia detalhada e informações sobre como explorar a atividade numa abordagem investigativa.

Palavras-chave: Biologia. Botânica. Potencial Alelopático. Atividade Investigativa. Ensino.

\section{ABSTRACT}

The work is a proposal for an investigative activity on the subject of Botany for high school Biology classes with the objective of evaluating the allelopathic potential of the aqueous extract of Eucalyptus on the germination of vegetable seeds (lettuce, arugula, radish and cabbage), through an experimental investigative activity. It presents detailed methodology and information on how to explore the activity in an investigative approach.

Keywords: Biology. Botany. Allelopathic Potential. Investigative Activity. Teaching.

Health and Biosciences, v.1, n.3, Dez. 2020

Disponível em: https://periodicos.ufes.br/healthandbiosciences 


\section{INTRODUÇÃO}

Há vegetais que liberam metabólitos que podem influenciar no desenvolvimento de espécies vizinhas, fenômeno de interferência denominado alelopatia, termo que deriva de duas palavras gregas: alleton, quer dizer mútuo e pathos, prejuízo. A alelopatia é o inverso da competição, pois enquanto a primeira implica na introdução de substâncias químicas, a segunda se refere à remoção do ambiente de recursos de crescimento, como luz, água, entre outros. Dentre as espécies com possível potencial alelopático, destacam-se as pertencentes ao gênero Eucalyptus, espécie arbórea nativa principalmente da Austrália (RICE, 1984).

Pereira (2003) testou extratos de folhas de Eucalyptus grandis com diferentes concentrações sobre três espécies de culturas agrícolas e observou uma inibição significativa dos mesmos sobre a germinação de alface e repolho. O órgão da planta de Eucalyptus que apresenta maior influência sobre a produção de aleloquímicos é a folha, pois as mesmas concentrações de extratos retiradas do caule e raízes foram testadas e não trouxeram resultados significativos na inibição ou estímulo à germinação. Apesar dos diversos estudos sobre alelopatia envolvendo espécies de eucalipto, não há consenso sobre o assunto. Uma das críticas é que seu possível efeito alelopático cria no solo condições desfavoráveis ao crescimento de outras plantas. Outra situação que tem provocado debates, tanto entre a comunidade científica quanto na sociedade em geral, são as dúvidas sobre os efeitos das florestas de eucalipto sobre os recursos hídricos do solo e mananciais.

Essa falta de consenso acerca do potencial alelopático do eucalipto, bem como sobre seus efeitos sobre o solo, pode representar um interessante objeto de estudo. As florestas de eucalipto fazem parte da paisagem do Norte do Espírito Santo e, portanto, do imaginário e do contexto sociocultural dos estudantes envolvidos na atividade descrita. Muitos são os questionamentos dos efeitos ambientais dessas plantas sobre o ambiente, situação que pode ser explorada para estimular a formulação de hipóteses e metodologias. Diante dessa constatação, a ideia manifestada pelos estudantes foi de realizar um experimento relacionado ao que observaram no percurso a uma aula de campo, um número restrito de espécies da flora no mesmo espaço. De fato, ideias como essas, que surgem para explorar a alelopatia por meio de procedimentos experimentais vêm sendo abordadas ao longo dos anos (RIZVI \& RIZVI, 1992).

No norte do Espírito Santo, o reflorestamento foi implantado há cerca de três décadas, devido a topografia que beneficiava o uso de mecanização ao manejo florestal, a existência de

Health and Biosciences, v.1, n.3, Dez. 2020

Disponível em: https://periodicos.ufes.br/healthandbiosciences

pág. 124 
suprimento hídrico aos abastecimentos, como também das condições do solo aos plantios de eucalipto, o que garantia uma alta produtividade. Entretanto, tudo isso desencadeou alterações nos ecossistemas locais e esse cenário faz parte do contexto sociocultural dos alunos que participaram da atividade descrita (SALGADO \& ALIMONDA, 2016).

Quando um estudante consegue associar um fenômeno aos conhecimentos científicos que tentam explicá-lo, de forma a buscar em fontes de pesquisa e interpretar pelas lentes de conhecimentos formais, está usando a habilidade que o leva a transpor do real ao conceitual, indicando a capacidade crítica de associar um fenômeno à sua explicação formal (VALDEZ, 2017).

\section{OBJETIVO}

$\checkmark$ Avaliar o potencial alelopático do extrato aquoso de Eucalyptus sobre a germinação de sementes de hortaliças (alface, rúcula, rabanete e couve), por meio de uma atividade experimental investigativa.

\section{METODOLOGIA}

\section{Materiais utilizados}

- 01 Liquidificador;

- Folhas jovens de eucalipto, retiradas das extremidades dos galhos e folhas maduras e /ou secas, coletadas do solo;

- 32 Placas de Petri;

- 02 frascos de $500 \mathrm{ml}$, com tampa;

- 01 litro de água destilada;

- 01 Peneira;

- $\quad$ Filtros de papel (suficientes para forrar o fundo das placas);

- Sementes de alface, rabanete, rúcula e couve, adquiridas em casa agropecuária;

- 01 Pinça;

- 01 almofariz com pistilo;

- 01 balança.

\section{Desenvolvimento}

A sequência didática investigativa (SDI) aqui apresentada segue a estrutura proposta por Carvalho (2013), segundo a qual criamos um contexto para a apresentação de um problema 


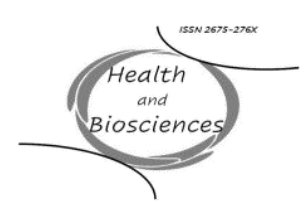

científico (experimental ou teórico). O problema instiga, estimula e provoca os alunos a partirem para a resolução. Ao longo do desenvolvimento da SDI são propostas atividades de sistematização por meio do material de apoio. Carvalho (2013) nos diz que o problema para ser significativo em procedimentos experimentais, introdutores de conceitos e/ou sistematizadores de dados, quando procura relacionar outros conceitos já assimilados, apresenta nova proposta teórica e diversificadas estruturas científicas que devem ser colocadas em ação na aprendizagem das Ciências.

Ainda segundo Carvalho (2013) um problema satisfatório é aquele que cria possibilidades à resolução e explicação de um fenômeno, ao levantamento de hipóteses, que relaciona a aprendizagem ao cotidiano e que oferece condições para que os conhecimentos apreendidos possam ser utilizados em outras disciplinas do conteúdo escolar.

Problematização: Apresentação de fotos e/ou vídeos, ou numa aula a campo a observação de uma área de monocultura de eucaliptos, instigando à percepção que a sua flora é menos abundante e diversificada e, consequentemente, sua fauna, o que limita a biodiversidade. Diante disso, os estudantes poderão ser motivados à discussão, mediada pelo professor e à proposição de algumas argumentações, tais como:

"Por que outras espécies de plantas têm dificuldades para se desenvolverem, juntamente com o eucalipto, no mesmo espaço?”

"Será que o eucalipto secreta substâncias que não deixam outras plantas germinarem e, assim, tem mais espaço, luz e água?”

De acordo com Valdez (2017) mesmo que um aluno não saiba como solucionar um problema, em virtude de considerar que não apresente habilidades, estimulá-lo a elaborar hipóteses pode levá-lo a articular seus conhecimentos e raciocinar sobre a situação problema. É importante que o professor estabeleça a noção de que todas as respostas e propostas de soluções são válidas, criando um espaço para participação e contribuições.

Nesta fase, os alunos são orientados à busca de argumentos por meio da pesquisa na literatura científica, para que sejam criadas possibilidades de confirmar ou refutar suas hipóteses, levando-os a fazer analogias de modo que os conhecimentos adquiridos esclareçam a problematização. O registro do levantamento de hipóteses é fundamental, bem como todas as

Health and Biosciences, v.1, n.3, Dez. 2020

Disponível em: https://periodicos.ufes.br/healthandbiosciences

pág. 126 
etapas de discussões. Seguidamente, são motivados a buscar procedimentos experimentais que possam testar as hipóteses levantadas. Uma atividade prática, experimental e investigativa pode ser proposta pelos estudantes, mediante pesquisa orientada, com o intuito de produzir mudanças conceituais (VALDEZ, 2017).

Com base nas hipóteses, esta atividade terá como principal objetivo testar a alelopatia do eucalipto na germinação de quatro hortaliças (alface, rabanete, rúcula e couve), selecionadas pelos estudantes por fazerem parte de sua nutrição. Daí, poderá surgir o interesse para estudo e análise do que representa o eucalipto, já que impede que outras plantas consigam se desenvolver no mesmo espaço. Além disso, essa atividade aguça a curiosidade por diferenciar as interações alelopatia e competição, sendo a primeira um termo novo e a segunda já estudada em Ecologia.

\section{Procedimento experimental:}

O papel de filtro será cortado para forrar as placas de Petri, sendo 2 camadas de papel de filtro por placa. As placas de Petri serão identificadas: sementes de alface + água/ sementes de alface + extrato de eucalipto; sementes de rúcula + água/ sementes de rúcula + extrato de eucalipto; sementes de rabanete + água/ sementes de rabanete + extrato de eucalipto; sementes de couve + água/ sementes de couve + extrato de eucalipto. Serão preparadas 4 repetições para cada tratamento, sendo, assim, 8 placas de cada semente (Figura 1).
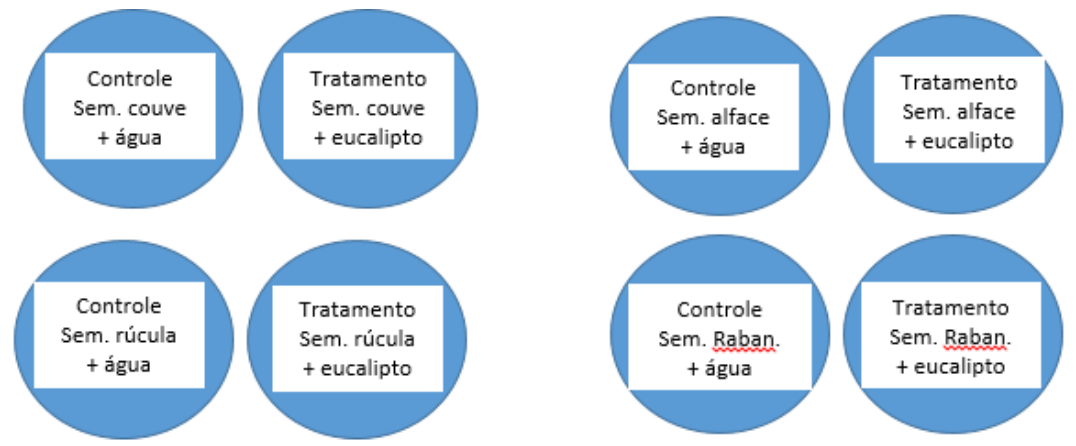

Figura 1. Desenho do experimento.

Preparo do extrato: colocar uma porção de 100 gramas de folhas de eucalipto (pode ser folhas jovens e maduras e/ou secas) no almofariz e macerar com o pistilo. Serão colocadas no liquidificador, juntamente com $500 \mathrm{~mL}$ de água destilada e trituradas por cerca de 2 minutos. Em seguida, coadas em uma peneira de malha fina e, após, em coador de papel. Este extrato será armazenado em frasco com tampa (Figura 2). 

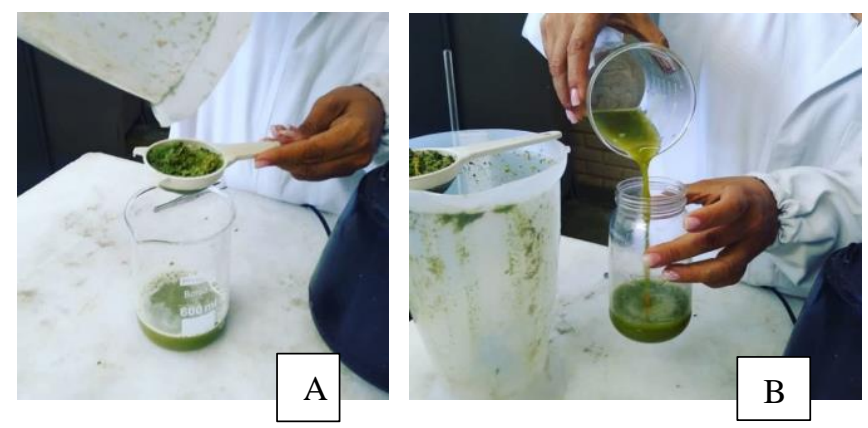

Figura 2. A. extrato de eucalipto obtido do maceramento e trituração de folhas jovens e secas; B. armazenamento do extrato. Fonte: Arquivo pessoal do autor.

Com o auxílio de uma pinça, serão colocadas 10 sementes em cada placa de Petri, organizadas em fileiras, com espaçamento semelhante entre elas, conforme a identificação da placa. Nas placas do grupo controle será acrescentado $5 \mathrm{~mL}$ de água destilada e no grupo experimental $5 \mathrm{~mL}$ de extrato de folhas de eucalipto (Figura 3).
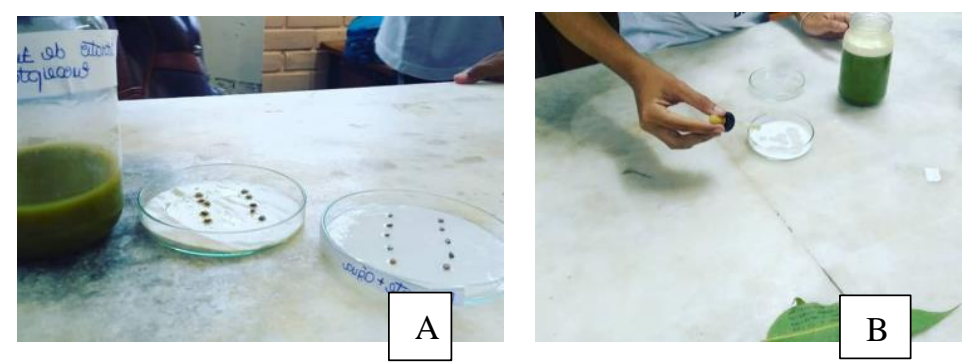

Figura 3. A. organização das sementes; B. placa regada com extrato. Fonte: Arquivo pessoal do autor.

As placas de Petri serão mantidas em local iluminado, mas não sob sol direto e em temperatura ambiente. Além disso, será observado diariamente o número de sementes germinadas em cada placa durante 8 dias, considerando que uma semente germina quando há emissão de sua radícula do embrião. $\mathrm{O}$ papel de filtro será mantido sempre úmido, acrescentando $5 \mathrm{~mL}$ a cada placa, a cada dois dias, ou quando necessário. A partir dessas observações diárias de germinação orienta-se a fazer contagem e registro, para que sejam criadas oportunidades do cálculo da média para cada condição. Mediante observação, sugerese como exemplo de resultados:

"Possivelmente as sementes regadas com água destilada continuarão se desenvolvendo, porém as que receberão extrato de eucalipto não demonstrarão nenhum sinal de germinação."

Health and Biosciences, v.1, n.3, Dez. 2020

Disponível em: https://periodicos.ufes.br/healthandbiosciences 
Assim, na avaliação de germinação de sementes de todas as hortaliças, supostamente verificar-se-á um efeito significativo do extrato de eucalipto em relação ao controle, como exemplificado a seguir (Figura 4).
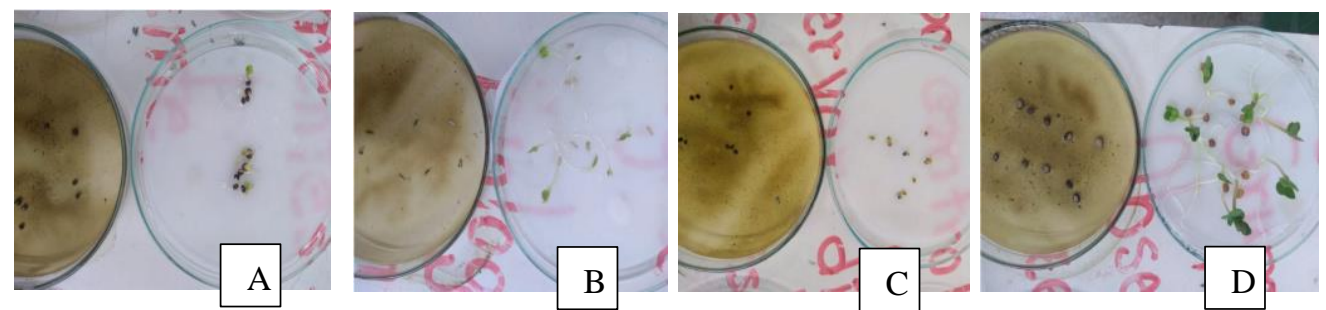

Figura 4. $8^{\circ}$ dia. Diferença visual entre os tratamentos. A. sementes de couve; B. sementes de alface; C. semente de rúcula; D. sementes de rabanete. Diferença visual entre os tratamentos. Fonte: Arquivo pessoal do autor.

\section{PONTOS INVESTIGATIVOS DA ATIVIDADE}

Para esta atividade ser investigativa o problema terá que ser escolhido e proposto pelos estudantes, relacionado ao contexto teórico estudado. Ao observarem presencialmente as florestas de eucalipto, que fazem parte do contexto sociocultural, os estudantes verificaram o número restrito de espécies da flora, no mesmo espaço. Entre as hipóteses que poderão ser levantadas pode-se exemplificar que:

"O eucalipto é uma árvore que absorve muita água do solo e, por isso, não permite que outras plantas compartilhem o mesmo espaço."

"O eucalipto produz alguma substância em suas raízes que impede a germinação e crescimento de outras plantas."

"O eucalipto não tem uma copa grande, o que faz com que a radiação solar incida diretamente no solo, causando seu aquecimento, o que impede que outras plantas se desenvolvam."

"É uma forma de competição por recursos do meio, principalmente a água."

Inicialmente os estudantes apresentavam conhecimentos sobre competição, entretanto desconheciam a existência do termo alelopatia, o que os instigou a pesquisar e a explorar mais sobre o assunto, culminando na proposta de realização de procedimentos experimentais, com o objetivo de comprovar ou refutar as hipóteses apresentadas. Caso não haja correlação com

Health and Biosciences, v.1, n.3, Dez. 2020

Disponível em: https://periodicos.ufes.br/healthandbiosciences 
conhecimentos prévios, o professor poderia induzir, no decorrer da discussão da problematização, analogias entre competição e alelopatia, o que estimularia a pesquisa.

De acordo com Valdez (2017), no ensino por investigação o agente central do processo de ensino-aprendizagem é o aluno e o professor tem papel de mediador ao longo de todo o processo, já que deixa de ser o detentor do conhecimento e passa a agir mais como orientador de pesquisa, criando situações instigantes, que despertem o interesse e que conduzam os alunos para que sejam responsáveis pelos seus estudos e aprendizagem. $\mathrm{O}$ autor enfatiza que no ensino por investigação se trabalha com problemas do cotidiano, nos quais os alunos estão intimamente inseridos e, assim, frequentemente, o professor terá que lidar com perguntas para as quais não há respostas, muitas vezes porque ainda não foram definidas àquele contexto. $\mathrm{O}$ autor cita que quando um estudante consegue associar um fenômeno aos conhecimentos científicos que tentam explicá-lo, de forma a buscar em fontes confiáveis de pesquisa e interpretar aquilo pelas lentes desses conhecimentos formais, está usando a habilidade que o leva a transpor do real ao conceitual, indicando a capacidade crítica e consciente de associar um fenômeno à sua explicação formal.

A atividade descrita representa um ensino por investigação, pois a busca de como fazer a experiência foi realizada pelos estudantes, sob a supervisão do professor, que retoma a discussão a partir dos resultados e conclusões. Concluiu-se que também se aprende com os erros ao retomar e refazer o raciocínio haja vista que na busca foram cometidos erros e enganos. $\mathrm{O}$ papel do aluno foi muito importante, uma vez que foi ele quem propôs o problema a ser resolvido e todas as outras etapas (Figura 5).

\begin{tabular}{|l|c|c|c|c|c|}
\hline & Grau 1 & Grau 2 & Grau 3 & Grau 4 & Grau 5 \\
\hline Problema & $\mathrm{P}$ & $\mathrm{P}$ & $\mathrm{P}$ & $\mathrm{P}$ & $\mathrm{A}$ \\
\hline Hipóteses & $\mathrm{P}$ & $\mathrm{P} / \mathrm{A}$ & $\mathrm{P} / \mathrm{A}$ & $\mathrm{A}$ & $\mathrm{A}$ \\
\hline Plano de trabalho & $\mathrm{P}$ & $\mathrm{P} / \mathrm{A}$ & $\mathrm{A} / \mathrm{P}$ & $\mathrm{A}$ & $\mathrm{A}$ \\
\hline Obtenção de dados & $\mathrm{A}$ & $\mathrm{A}$ & $\mathrm{A}$ & $\mathrm{A}$ & $\mathrm{A}$ \\
\hline Conclusões & $\mathrm{P}$ & $\mathrm{A} / \mathrm{P} /$ Classe & $\mathrm{A} / \mathrm{P} /$ Classe & $\mathrm{A} / \mathrm{P} /$ Classe & $\mathrm{A} / \mathrm{P} /$ Classe \\
\hline
\end{tabular}

Figura 5. Graus de liberdade de professor (P) e alunos (A) em atividades experimentais (CARVALHO et al., 2010, p. 55).

Segundo Carvalho et al. (2010) esta atividade se qualifica no grau 5, no qual o problema foi escolhido e proposto pelo aluno, bem como todas as etapas da ação investigativa. Perante o 


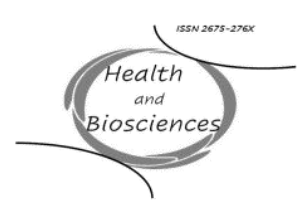

seu desenvolvimento, os alunos, inicialmente, levantaram o problema oriundo da observação que fizeram durante viagem à aula de campo. Observaram que entre as monoculturas de eucalipto, que se estendem até o local da aula, Parque Estadual de Itaúnas, Unidade de Conservação de Proteção Integral, localizada no município de Conceição da Barra, ES, não havia biodiversidade da flora e, consequentemente, da fauna. A partir das hipóteses discutidas e analisadas em grupos, os alunos pesquisaram e propuseram o desenvolvimento do experimento efeito do extrato de eucalipto na germinação de hortaliças. Através da pesquisa constataram que o livro didático do ensino médio que utilizam não aborda o termo alelopatia e sim, amensalismo ou antibiose.

Ao final do experimento houve nova discussão a respeito dos resultados observados e confirmação de que parte das hipóteses levantadas havia interpretação errônea. Por exemplo, a maioria dos alunos considerava que o efeito principal da redução do número de espécies que compartilham os mesmos recursos do eucalipto era devido ao fato de levar vantagem na competição pelos recursos do meio, principalmente a água. Embora não se possa concluir, a partir desta atividade, que os compostos aleloquímicos provenientes do eucalipto influenciam de forma negativa na germinação da alface, rúcula, rabanete e couve, pode-se sugerir que Eucalyptus possui um potencial de inibição na germinação dessas hortaliças. Esse resultado contribuiu para que os estudantes buscassem na literatura possíveis explicações para os efeitos alelopáticos e abriu espaço para abordar as interações ecológicas de forma investigativa.

Ao analisarem os resultados dos procedimentos experimentais adotados no desenvolvimento desta atividade, os alunos concluíram que competição por recursos não deve ser confundida com alelopatia, que se refere a qualquer efeito direto ou indireto danoso ou benéfico que uma planta, incluindo microrganismos, exerce sobre outra pela produção de compostos químicos liberados no ambiente. O que diferencia a alelopatia da competição entre plantas é o fato de a competição reduzir ou remover do ambiente um recurso de crescimento necessário a ambas às plantas, como a luz, água, nutrientes, entre outros, enquanto a alelopatia ocorre pela adição de um fator ao meio.

\section{CONSIDERAÇÕES}

Os alunos serão participantes ativos, desde a etapa de criação do problema à etapa de análise dos resultados, discussão e registro, já que a atividade experimental permitirá melhor 
compreensão do conteúdo teórico abordado em sala de aula e motivará o hábito de pesquisar, refletir, questionar e buscar soluções para os problemas propostos.

O aluno se tornará construtor do seu conhecimento, possibilitando a troca de saberes e a discussão na qual o professor tem um papel de mediador à formulação do conhecimento, permitindo o questionamento, estimulando o espírito investigativo e facilitando a interação do conteúdo teórico à prática, pois os mesmos poderão conseguir correlacionar ao conteúdo de interações ecológicas.

Possivelmente os alunos iriam se deparar com dificuldades nas etapas de desenvolvimento da atividade investigativa por estarem habituados a receber o conteúdo pronto, como "receitas de cozinha", metodologia de ensino diretivo, no qual o professor apresenta o problema e as hipóteses, e mostra todos os passos, restando aos mesmos somente acatar.

Havendo disponibilização de tempo, os procedimentos experimentais poderiam propor o tratamento em leguminosas, como o feijão por exemplo, já que foi feito apenas com hortaliças e, além disso, poderia também testar a influência da luz na germinação das sementes.

\section{AGRADECIMENTOS}

O presente trabalho foi realizado com o apoio da Coordenação de Aperfeiçoamento de Pessoal de Nível Superior - Brasil (CAPES) - Código de financiamento 001.

\section{REFERÊNCIAS BIBLIOGRÁFICAS}

1. CARVAlHO AMP. O ensino de ciências e a proposição de sequências de ensino investigativas. In: Carvalho AMP, Oliveira CMA, Scarpa DL, Sasseron LH, Sedano L, Batistoni e Silva M, Capecchi MCVM, Abib MLVS, Briccia V editores. Ensino de ciências por investigação: condições para implementação em sala de aula. São Paulo: Cengage Learning, 2013, p.1-20.

2. CARVALHO AMP, RICARDO EC, SASSERON LH, ABIB MLVS, PIETROCOLA M. Ensino de Física. Coleção Ideias em Ação. São Paulo: Cengage Learning, 2010, 158p. 
3. PEREIRA GP, COSTA ASV, BORÉM RAT. Efeitos de extratos aquosos de Eucalyptus grandis na germinação de sementes de três culturas agrícolas. UFLA, Lavras, 2003. Disponível em: <http://sebecologia.org.br/revistas/indexar/anais/viiceb/resumos/214a.pdf $>$. Acesso em 25 de setembro de 2019.

4. RICE EL. Allelopathy, 2.ed., New York: Academic Press, 1984, 422p.

5. RIZVI SJH, RIZVI V. Exploração de aleloquímicos na melhoria da produtividade das culturas. In: Rizvi SJH, Rizvi V editores. Alelopatia: aspectos básicos e aplicados, Londres: Chapman e Hall, 1992, p.443-472.

6. SALGADO IM, ALIMONDA HA. Reflexões sobre o monocultivo de eucalipto em Conceição da Barra (ES-Brasil) e seus efeitos desfavoráveis. Est Soc Agricult 24(2): 523 $544,2016$.

7. VALTEZ VR. Ensino por investigação na sala de aula: uma matriz de objetivos educacionais. Dissertação (Mestrado Profissional em Ensino de Ciências), Programa de Pós-Graduação em Ensino de Ciências, Universidade de Brasília, Brasília, 2017, 164p. 